\title{
A New Genus and Species of the Subfamily Tachiniscinae (Diptera, Tephritidae) from Australia
}

\author{
VALERY A. KORNEYEV \\ I.I.Schmalhausen Institute of Zoology, National Academy of Sciences of Ukraine, \\ Bogdan Chmielnicki St. 15, 01601 Kiev, Ukraine \\ valery.korneyev@gmail.com
}

\begin{abstract}
A parasitic fly Aliasutra australica new genus and species is described, and the subfamily Tachiniscinae is recorded from Australia for the first time. The new species superficially resembles pyrgotid flies by lacking frontal setae and wing pattern, and by having numerous proepisternal setae and brownish yellow body. It possesses a unique structure of female terminalia, which is a synapomorphy of the Tachiniscinae, and the incomplete costal vein, long tubular phallus and elongate spermathecae, which are considered synapomorphies of the tribe Tachiniscini, and is placed in that tribe.
\end{abstract}

KorneyeV, VAlERY A. 2012. A new genus and species of the subfamily Tachiniscinae (Diptera, Tephritidae) from Australia. Records of the Australian Museum 64(3): 159-166.

KEYwORDS: Tephritoidea; Tephritidae; Tachiniscinae; Tachiniscini; new genus; new species; Australia.

Tephritid flies of the subfamily Tachiniscinae are rare in collections and are poorly known biologically, but they are important to understanding the phylogeny of the Tephritidae, as they appear to be the earliest branch of the family. As far as known, some species are parasites of caterpillars of saturniid moths, and this is believed to be true for all the Tachiniscinae, as they share similar structure of female ovipositor. Such uncommon habits, different from other Tephritidae, which have phytophagous or saprophagous larvae, along with odd appearance of some species mimetic of bumblebees or wasps, has resulted in establishment of a nominal family Tachiniscidae, which later was shown to include some species of typically tephritid habitus and synonymised with Tephritidae (Korneyev, 1999). All hitherto known data were summarised by Korneyev \& Norrbom (2006).

The subfamily included 20 described species belonging to 9 genera of two tribes, Tachiniscini and Ortalotrypetini, which were known to occur in the Afrotropical and
Neotropical Regions and also in south eastern provinces of China, usually considered to belong in the Palaearctic Region. An undescribed genus and species related to Tachinisca is recognised in collections from the Oriental Region (T. Saigusa, pers. comm.).

While studying the Diptera collection at the Australian Museum (Sydney), VAK found a series of odd flies recognized by David K. McAlpine as a new genus and species, superficially resembling some Pyrgotidae and therefore preliminarily sorted with the pyrgotid genera. Detailed study of female genitalia shows that they possess essential characters of the subfamily Tachiniscinae. The new taxa are described below.

Type material is deposited in the collections as follows:
AMS
Australian Museum, Sydney;
SIZK I. I. Schmalhausen Institute of Zoology, Kiev;
MNVM Museum of Victoria, Melbourne. 